\title{
A FALA DOS EXCLUÍDOS EM TEMPOS LÍQUIDOS
}

\author{
Analice Assunção de Souza Nunes? \\ Sandra Fernandes Leite 2
}

\section{RESUMO}

O presente artigo foi resultado de um recorte da pesquisa de Iniciação Científica da Faculdade de Educação da Unicamp e está baseado na obra de Garcia e Valla, publicado no Caderno do Centro de Estudos Educação e Sociedade CEDES n.38, no ano de 1996, cujo conteúdo abordou subalternidade, poder e saber. Tratase de tema recorrente na sociedade contemporânea, questão agravada nestes tempos líquidos, em que a fluidez, indefinições e volatilidade fundamentam as relações da sociedade ocidental, conforme explicita a obra de Bauman. Para a reflexão foi considerada a concepção de Paulo Freire para a educação, cuja função emancipadora possibilita que o educando se constitua como cidadão crítico, partícipe de movimento coletivo e emancipador. A metodologia adotada foi a pesquisa bibliográfica e teve como objetivo refletir sobre a atualidade da concepção freireana de educação.

Palavras-chave: Subalternidade. Educação freireana. Educação emancipatória.

\section{THE SPEECH OF THE EXCLUDED IN LIQUID TIMES}

\begin{abstract}
This study was a result of a research leased in Education College from Unicamp and it was based in Garcia e Valla, published in Caderno CEDES n.38 during the year of 1996, whose content addressed the subalternity, power and knowledge. It is a recurring theme in contemporary society an issue that was aggravated in liquid times, which fluidity, indefiniteness and volatility foments the relations of western society, as explicit in the work of Bauman. For reflection, Paulo Freire's conception of education was consideres, whose emancipatory function enables the student to become a critical citizen, a participant in the collective and emancipatory movement. The methodology adopted was bibliographic research and the aim was think over about the topicality of Freire conception of education.
\end{abstract}

Keywords: Subalternity. Freires' education. Emancipatory education.

\footnotetext{
1 Pós-graduanda. Universidade Estadual de Campinas. Professora de Educação Artistica, Instituto Musical de São Paulo, 1979; Orcid iD: https://orcid.org/0000-0002-6516-7595. E-mail: analicenunes@vol.com.br

2 Professora doutora em Educação pela Universidade Estadual de Campinas. Orcid iD: https://orcid.org/0000-0002-9213-6508. E-mail: sflleite@unicamp.br
} 


\section{EL DISCURSO DE LOS EXCLUIDOS EN TIEMPOS LÍQUIDO}

\section{RESUMEN}

Este estúdio fue el resultado de una investigación arrendada en el Colegio de Educación de la Unicamp y se basó en García e Valla, publicado en Cuaderno CEDES n.38 durante el año de 1996, cuyo contenido abordaba la subalternidad, el poder y el conocimiento. Es un tema recurrente en la sociedad contemporánea, un tema que se vio agravado en épocas líquidas, cuya fluidez, indefinición y volatilidad fomentan las relaciones de la sociedad occidental, como lo expresa el trabajo de Bauman. Para reflexionar, se tuvo en cuenta la concepción de la educación de Paulo Freire, cuya función emancipatoria permite al estudiante convertirse en un ciudadano crítico, un participante en el movimiento colectivo y emancipatorio. La metodología adoptada fue la investigación bibliográfica y el objetivo fue reflexionar sobre la actualidad de la concepción educativa de Freire.

Palabras claves: Subalternidad. Educación de Freire. Educación emancipadora.

\section{INTRODUÇÃO}

O presente artigo considerou o texto de Garcia e Valla (1996), "A fala dos excluídos", publicado no Cadernos do Centro de Estudos Educação e Sociedade CEDES n. 38, ponto inicial da reflexão, já que a obra pondera sobre as dinâmicas que permeiam as relações entre os que são historicamente silenciados e os pesquisadores e agentes que definem o que é conhecimento e saber.

O texto de Garcia e Valla (1996), inspirador deste artigo, é parte da pesquisa efetuada na Faculdade de Educação da Universidade Estadual de Campinas UNICAMP, na Iniciação Científica intitulada "A Educação de Jovens e Adultos: uma análise das publicações Cedes", constituída no levantamento e analise de artigos publicados na Revista Educação \& Sociedade e Cadernos CEDES concernentes à Educação de Adultos e da modalidade Educação de Jovens e Adultos. A pesquisa construiu uma série histórica, identificando as principais correntes teóricas presentes relativa aos artigos publicados entre 1978 e 1996, uma vez que esses circularam apenas na revista impressa e, portanto, pressupõe-se que tenham um alcance mais restrito na atualidade em razão da facilidade dos levantamentos disponíveis na internet. 
Pretendeu-se verificar como a educação, segundo a concepção de Paulo Freire (1985, 1986, 1993, 2000, 2001a, 2001b, 2002, 2006a, 2006b), pode contribuir para que os excluídos, conforme análise do artigo de Garcia e Valla (1996), possam ter sua fala registrada na sociedade atual; possam ser capazes de inserir-se nas dinâmicas e relações sociais, com a valorização de sua identidade e características; respeitando seus saberes e conhecimentos, em um movimento de protagonismo.

Através de pesquisa bibliográfica em estudos que retratam a sociedade contemporânea, buscou-se fundamentar a reflexão em obras que apresentam as características marcantes da segunda década do século XXI. As obras de Sennett (2009), Bauman (2007), Guattari (2001) e lanni (1999) foram consideradas para aprofundamento das peculiaridades do capitalismo pós-moderno e possibilitaram uma compreensão das dinâmicas marcantes na vida dos indivíduos, na atualidade.

O presente artigo tem como objetivo entender a fala dos excluídos, ou seja, das pessoas historicamente silenciadas los analfabetos, os poucos escolarizados, os pobres, os negros, os desempregados) referenciada no trabalho de Garcia e Valla (1996), como podem se tornarem protagonistas; como podem ser registradas e consideradas nas relações e dinâmicas da sociedade atual. Apresenta a educação freireana, que poderá possibilitar um movimento emancipador, que liberte o educando e o capacite para ações coletivas e solidárias.

Este artigo pretende ponderar como se expande o contingente de excluídos: os direitos conquistados como resultado de luta da sociedade civil e que foram explicitados na Constituição Federal de 1988 e foram modificados: a reforma Trabalhista, que possibilitou a terceirização nas relações de trabalho com perdas para o trabalhador, além de outras que deverão dificultar ainda mais a vida dos excluídos, como a discussão sobre a redução da maioridade penal e a reforma na previdência, que onerarão pesadamente os trabalhadores e outras parcelas da sociedade, que puderam no período pós ditadura militar, ter condições de melhorar suas 
expectativas e qualidade de vida, através de inserção no mercado e com a possibilidade de ampliar sua vida escolar.

A educação oferecida aos excluídos los analfabetos, os poucos escolarizados, os pobres, os negros, os desempregados) tem atraído grandes empresas, que veem no mercado educacional um filão bastante promissor para seus negócios, tornando a educação, que é um direito conquistado como educação pública, gratuita, laica e de qualidade, confirmada na Constituição Brasileira de 1988, ser totalmente incorporada por empresas que utilizam a educação como processo lucrativo, pervertendo a finalidade e o objetivo final da Educação, que é permitir ao educando aquisição de conhecimentos e dinâmicas para atuar como cidadão e transformar a sociedade em justa e igualitária.

O artigo está organizado em cinco tópicos. O primeiro tópico é 0 mundo contemporâneo, apresentando considerações de Sennett (2009), Bauman (2007), Guattari (2001) e Ianni (1999) sobre a sociedade. O tópico seguinte: A fala dos excluídos aborda o trabalho de Garcia e Valla (1996), refletindo como os excluídos são desconsiderados nas dinâmicas sociais atuais. A seguir é apresentada A concepção Freireana de Educação, discorrendo sobre elementos fundamentais para a práxis de educação freireana. Em Novas perspectivas: a Pedagogia da Terra e a Teoria Crítica, comenta-se sobre a ecopedagogia e a resistência de uma educação contra hegemônica, representada pela teoria crítica. Finalmente em Considerações Finais são apresentadas as reflexões decorrentes da validade e da necessidade de se adotar a concepção freireana de educação, na atualidade.

\section{O mundo contemporâneo}

A sociedade ocidental tem vivenciado tempos de grande instabilidade econômica e social. A estrutura pós capitalista engloba negócios no mundo todo, com empreendimentos multinacionais, em relações de mercado que desconsideram territórios e fronteiras. 
As dinâmicas no trabalho são impactadas pelos mecanismos opressores de imprevisibilidade, insegurança e altamente flexíveis, proporcionando ao indivíduo uma sensação de insegurança e angústia.

lanni (1999) discorre sobre as condições de opressão na sociedade contemporânea:

\begin{abstract}
$\mathrm{Na}$ época do capitalismo global surgem novas e "inesperadas" formas de pauperismo, que têm sido descritas como manifestações de "pobreza", "miséria", "fome". São manifestações novas e renovadas do processo de pauperização inerente à fábrica da sociedade, ao modo capitalista de produção [...] Com os novos surtos de desenvolvimento intensivo e extensivo do capitalismo no mundo, ocorrem novos surtos de urbanização. O modo urbano de vida, sociabilidade e cultura também se generaliza, invadindo meios rurais, modos de vida agrários, sociabilidade e cultura do campo. Isto significa que o mundo agrário se altera, modifica, dilui. Ocorre uma espécie de dissolução da sociedade agrária, continuamente permeada de surtos de urbanização [...] Em boa parte dos casos, o indivíduo situa-se na cidade como em um caleidoscópio em contínuo movimento, veloz e errático. Como ela se organiza, funciona e transforma de acordo com processos dos quais o indivíduo pouco sabe, este se perde ou assusta-se, defende-se ou isola-se. Diante do vasto bombardeio de signos, significados e conotações, difíceis de decodificar, o indivíduo pode levar o anonimato a fórmulas inimagináveis, a extremos de paroxismo (IANNI, 1999, p.60-64).
\end{abstract}

As cidades passam a ter um significado distinto, de acordo com as classes sociais em que estejam inseridos os indivíduos. Os espaços urbanos, para a elite, são concebidos em locais delimitados (espaços interditados), arquitetados para serem limpos, agradáveis, bonitos e seguros. Ao restante da população (os trabalhadores, os pobres, os mais desfavorecidos) sobra a periferia da cidade, sem infraestrutura e sem os equipamentos dos centros urbanos; sem o oferecimento dos serviços públicos (saúde, educação). "Os núcleos urbanos se estruturam entre os polos dos guetos urbanos voluntários e involuntários" (BAUMAN, 2007, p.78).

Os espaços urbanos constituem-se em locais desagregados de significado pessoal, as relações são predominantemente virtuais. Bauman (2007) destaca:

As pessoas da "camada superior" não pertencem ao lugar que habitam, pois suas preocupações estão (ou melhor, flutuam e navegam à deriva) em outro lugar. Pode-se imaginar que, além de

Revisła Exitus, Santarém/PA, Vol. 9, N. 5, p. 503 - 528, Edição Especial 2019. 
ficarem sozinhas, e, portanto, livres para se dedicarem totalmente a seus passatempos, e terem os serviços indispensáveis a seu conforto diário assegurado (como quer que seja definido), elas não têm outros interesses investidos na cidade em que se localizam suas residências. A população da cidade não é sua área de pastagem, a fonte de sua riqueza e, portanto, também uma ala sob sua guarda, cuidado e responsabilidade, como costumava ser para as elites urbanas de outrora [...] o mundo em que vive a outra camada de moradores da cidade, a camada "inferior", é o exato oposto da primeira. Em agudo contraste com o estrato superior, caracteriza-se por ter sido cortado da rede mundial de comunicação à qual as pessoas de "camada superior" estão conectadas e à qual estão sintonizadas suas vidas. Os cidadãos urbanos da camada inferior são "condenados a permanecerem locais" - e, portanto se pode e deve esperar que suas atenções e preocupações, juntamente com seus descontentamentos, sonhos e esperanças se concentrem nos "assuntos locais". Para eles, é dentro da cidade que habitam que a batalha pela sobrevivência, e por um lugar decente no mundo, é lançada, travada e por vezes vencida, mas na maioria das vezes perdida (BAUMAN, 2007, p.80-81).

Os tempos líquidos caracterizam-se por relações voláteis, constituídas por meios virtuais; as certezas profissionais e a segurança da carreira consolidada não mais existem, tudo pode ser alterado, conforme as regulações de mercado; são tempos permanentemente fluidos, voláteis e inseguros, transformam os indivíduos em pessoas solitárias e segregadas, distantes das relações solidárias e coletivas, quando as relações são constituídas primordialmente por meios virtuais, sem uma efetivação de encontros reais:

Quanto mais as pessoas permanecem num ambiente uniforme - na companhia de outras "como elas" com as quais podem ter superficialmente uma "vida social" praticamente sem correrem o risco da incompreensão e sem enfrentarem a perturbadora necessidade de traduzir diferentes universos de significado -, mais é provável que "desaprendam" a arte de negociar significados compartilhados e um modus covivendi agradável [...] Já que os estranhos tendem a levar suas vidas na companhia uns dos outros por um longo período, independentemente das voltas e reviravoltas da história urbana, a arte de viver em paz e feliz com a diferença e de se beneficiar da variedade de estímulos e oportunidades ganha imensa importância entre as habilidades que um residente da cidade necessita (e deveria) aprender e empregar [...] compartilhar a experiência é inconcebível sem um espaço comum. Os medos contemporâneos mais assustadores são os que nascem da incerteza existencial. Suas raízes se fincam muito além das condições da vida urbana, e o que quer que se faça dentro da cidade e na escala do espaço urbano e dos recursos administrados pela cidade para cortar essas raízes ficará aquém do que seria necessário para esse empreendimento (BAUMAN, 2007, p.94/97).

Revisła Exitus, Santarém/PA, Vol. 9, N. 5, p. 503 - 528, Edição Especial 2019. 
Tais perspectivas retratam o caráter efêmero das relações e apresentam como nas sociedades urbanas as manifestações artísticas tendem a serem incorporadas pela indústria cultural e os processos culturais tradicionais se deterioram (ADORNO; HORKHEIMER, 2002).

Nunes (2017) apresenta a obra de Sennett (2009), que pondera sobre a concepção do pronome "nós". Enfatizando a importância da constituição dos significados de vida, da confiança e da constituição do coletivo, Sennett (2009) discorre:

\begin{abstract}
Hoje, no novo regime de tempo, esse uso do nós se tornou um ato de autoproteção. O desejo de comunidade é defensivo [...] sendo a arquitetura comunal mais importante que as muralhas contra uma ordem econômica hostil. Claro, é quase uma lei universal que o nós pode ser usado como defesa contra a confusão e a deslocação [...] O laço de confiança, como vimos, desenvolve-se informalmente nas brechas e fendas das burocracias à medida que as pessoas aprendem de quem podem depender. Os laços de confiança são testados quando as coisas dão errado e a necessidade de ajuda se torna aguda (SENNETT, 2009, p.165-169).
\end{abstract}

Tanto Sennett (2009) como Bauman (2007) enfatizam a necessidade humana de convívio, de compartilhamento, de experiências comunitárias. A essência humana é preservada quando há o exercício da comunhão, da consciência do coletivo.

O Fórum Econômico Mundial, que em 2018 contou com o presidente dos Estados Unidos, defendendo a supremacia econômica americana, teve como tema nas últimas reuniões, acontecidas em janeiro de 2018, "criando valores comuns, num mundo fraturado"3. Sennett (2009), comentando sobre a elite econômica reunida em Davos/Suíça, para o Fórum Econômico Mundial, que reúne os principais líderes empresariais e políticos, para decisões envolvendo as economias das grandes potências e suas preocupações com as organizações comunais, e como se ressentem e temem ações coletivas demandadas por grupos oprimidos, aborda o sentimento que o pronome nós evoca naqueles representantes da elite hegemônica:

3Disponível em <http://www.valor.com.br/internacional/5261 187/trump-falara-no-ultimo-diado-forum-de-davos> acessado em 28/03/2018.

Revista Exitus, Santarém/PA, Vol. 9, N. 5, p. 503 - 528, Edição Especial 2019. 
[...] tive uma espécie de epifania em Davos, ouvindo os governantes do reino flexível. Também para eles, "nós" é um pronome perigoso. Eles habitam confortavelmente a desordem econômica, mas temem o confronto organizado. Temem, claro, o ressurgimento dos sindicatos, mas ficam aguda e pessoalmente desconfortáveis, mexendo-se ou evitando olhar nos olhos, ou retirando-se para trás de anotações, se obrigados a discutir as pessoas que, em seu jargão, "foram deixadas para trás". Sabem que a grande maioria dos que mourejam no regime flexível é deixada para trás, e claro que lamentam isso. Mas a flexibilidade que festejam não dá, não pode dar, qualquer orientação para a conduta de uma vida comum (SENNETT, 2009, p. 175-176).

Sennett (2009) finaliza sua obra com reflexões sobre a importância do fortalecimento do coletivo, do sentido de pertencimento e do pronome nós:

[...] aprendi com o amargo passado radical de minha família: se ocorre mudança, ela se dá no chão, entre pessoas que falam por necessidade interior, mais do que por levantes de massa. Que programas políticos resultam dessas necessidades interiores, eu simplesmente não sei. Mas sei que um regime que não oferece aos seres humanos motivos para ligarem uns para os outros não pode preservar sua legitimidade por muito tempo (SENNETT, 2009, p. 175176).

As caracterizações da sociedade contemporânea, apresentadas nas obras de Bauman (2007) e Sennett (2009) expõem a fragilidade das relações humanas, o caráter transitório das relações quando se assume a forma como se constitui a sociedade atual.

Guatarri (2001) ressalta a dicotomização proporcionada pela mídia e o aprofundamento das desigualdades, agora também virtuais:

A acelerada midiatização do conjunto das sociedades tende assim a criar um hiato cada vez mais pronunciado entre essas diversas categorias de população. Do lado das elites, são colocados suficientemente à disposição bens materiais, meios de cultura, uma prática mínima de leitura e da escrita e um sentimento de competência e de legitimidade decisionais. Do lado das classes sujeitadas, encontramos, bastante frequentemente, um abandono à ordem das coisas, uma perda de esperança de dar um sentido à vida (GUATARRI, 2001, p. 46).

A noção do coletivo também é referenciada por Guatarri (2001), que ressalta sua relevância para a humanidade:

A noção de interesse coletivo deveria ser ampliada a empreendimentos que em curto prazo não trazem "proveito" a ninguém, mas em longo prazo são portadores de enriquecimento 
processual para o conjunto da humanidade. É o conjunto do futuro da pesquisa fundamental e da arte que está aqui em causa (GUATARRI, 2001, p.51).

No Brasil além da crise financeira temos encaminhamentos de governo que precariza ainda mais a situação dos excluídos. Na área da educação tem-se evidente o descaso: no governo Temer já passaram pelo Ministério da Educação três ministros, indicando a falta de continuidade de estratégias e políticas para a área. A modalidade Educação de Jovens e Adultos, que atende aos excluídos (pobres, adultos, marginalizados, não escolarizados) tem sido relegada nas discussões de políticas públicas; na maioria das vezes é apenas citada, sem se considerar suas especificidades. As discussões sobre as alterações ou reformas na Educação são construídas sem um acompanhamento dos profissionais da educação.

\section{A fala dos excluídos}

A importância da obra que inspira este trabalho A fala dos excluídos, de Garcia e Valla (1996) é exatamente reconhecer os desfavorecidos/excluídos los analfabetos, os pouco escolarizados, os desempregados, os pobres, os marginais) e entender como sua fala poderá ser propagada e representar uma marca significativa nas relações que constituem e formam o mundo contemporâneo.

Na análise da conjuntura social, o trabalho de Garcia e Valla (1996) menciona características que ainda não se modificaram nestes últimos vinte anos, sendo ainda atuais e marcantes:

A tendência aponta para a internacionalização das indústrias e das tecnologias de ponta que, não sendo mais nacionais, dispensarão a criatividade e a inventividade de cidadãos nacionais e os "recursos nacionais" de cada país. Os governos nacionais, especialmente os do Terceiro Mundo, passarão a ter a difícil tarefa de incentivar um mínimo de coesão entre os vários segmentos da população, pois a alternativa será o acúmulo de riqueza ainda maior entre os "habilidosos" e um declínio de padrão de vida ainda maior para aqueles que não teriam o que oferecer [...] A tendência desta nova ordem mundial é o deslocamento da produção do centro, onde a classe trabalhadora tem poder de pressão, para zonas de alta repressão e baixos salários, com uma produção dirigida aos setores privilegiados da economia global. Desta forma, grande parte da 
população mundial poderia tornar-se supérflua para a produção e até como mercado (GARCIA; VALLA, 1996, p.13).

Ressalta-se que o texto de Garcia e Valla (1996) apresenta análises que são atuais, destacando como as relações e dinâmicas sociais se constituem na sociedade. A crise mundial que afeta intensamente as relações comerciais internacionais, impacta fortemente no crescimento das economias de todos os países, ocasionam um desaceleramento dos processos econômicos nas cadeias produtivas. Acrescem-se, ainda, as reformas em curso, que fragilizam os mais desfavorecidos: a reforma trabalhista, retirando direitos conquistados; a reforma previdenciária, onerando a vida do trabalhador, que perde valor em sua aposentadoria e a vê cada vez mais distante; as reformas na educação, que desestruturam os processos educativos e precarizam ainda mais a educação pública.

Garcia e Valla (1996) explicitam como os que estudam e trabalham com os mais desfavorecidos apreendem as falas emitidas pelos excluídos:

O que de um modo geral acontece é a imposição de um conhecimento que subalterniza o conhecimento popular, impedindo-o de se manifestar. Seria importante voltar a Gramsci, à sua tão conhecida afirmação de que "o elemento popular 'sente', mas nem sempre compreende ou sabe". O elemento intelectual 'sabe' mas não compreende ou, particularmente, 'sente'". E Gramsci acrescenta que embora o intelectual acredite que se possa "saber sem compreender e, especialmente, sem sentir", o saber é o resultado da vinculação dialética das paixões elementares do povo às leis da história. Fica clara a vinculação entre saber-políticamovimento histórico. O saber é, portanto, um espaço de luta pelo poder (GARCIA; VALLA, 1996, p.10).

A obra Garcia e Valla (1996) é contundente quando reflete sobre a atuação dos que estudam e trabalham com os excluídos, citando Foucault (1979):

O que os intelectuais descobriram é que as massas não têm necessidade deles para saber: sabem claramente, perfeitamente, muito melhor do que eles: e o afirmam extremamente bem. Porém existe um sistema de poder que obstaculiza, que proíbe, que invalida este discurso e este saber. Poder que não está somente nas instâncias superiores da censura, mas que se funde mais profundamente, mais sutilmente em toda a malha da sociedade (FOUCAULT (1979) apud GARCIA; VALLA, 1996, p. 12). 
Reconhecer na fala dos excluídos a criticidade ou entender as dinâmicas de contestação ao sistema vigente, que pode ser um comportamento aparentemente despolitizado ou alienante, possibilita dar valor e entendimento ao modo de agir distinto, compreender as razões ou significados implícitos.

A importância de pesquisadores e agentes que atuam junto às classes desfavorecidas é ressaltada:

Os saberes populares trazem dialeticamente possibilidades de manutenção do status quo e de transformação, na medida em que podem ser acríticos e reforçadores de mitos e dependências, mas podem também ser críticos e desmitificadores de ideologia dominante. Esta é uma questão fundamental quando se trabalha com os grupos populares - identificar os conteúdos revolucionários das falas e ações populares e contribuir para que estes núcleos se ampliem e fortaleçam, num diálogo em que os grupos populares e os "intelectuais " se enriquecem e avançam (GARCIA; VALLA, 1996, p.12).

Os autores Garcia e Valla (1996) alegam que as pesquisas se iniciam com hipóteses já consolidadas e as práticas reverenciam-nas, dificultando um outro entendimento:

O desafio continua - para trabalhar junto com os grupos populares há que se romper com a onipotência historicamente construida, assumindo o conteudo de classe presente na relação entre intelectuais e "não intelectuais" e se abrir para o "outro" numa relação de troca entre diferentes, que se encontram na luta comum contra o poder que obstaculiza, que proibe, que invalida o discurso e o saber populares (GARCIA; VALLA, 1996, p. 12)

Garcia e Valla (1996) defendem uma relação distinta: onde o discurso dos excluídos seja entendido com os significados emanados por eles, com uma dinâmica em que intelectuais e excluídos assumam relação de troca entre diferentes; quando os intelectuais poderão sentir, e o registro da fala traduza o sentir dos excluídos, permitindo uma amplitude de compreensão dos significados. É importante diminuir o abismo entre as pesquisas realizadas na Universidade e a realidade dos excluídos. 


\section{A concepção Freireana de Educação}

As obras de Paulo Freire (1985, 1986, 1993, 2000, 2001a, 2001b, 2002, 2006a, 2006b), concebem os educandos como produtores de vida e de cultura e que a ação pedagógica tem como objetivo propiciar uma visão consciente e crítica da realidade social que os cerca, para uma ação transformadora, no sentido de eliminar as relações opressoras, estabelecendo novas dinâmicas sociais. Neste sentido a educação é dialógica, constituída por educadores que em uma relação respeitosa, reconhecem os saberes e conhecimentos que os educandos possuem, e desvelam a realidade, em busca da educação libertadora, emancipadora; duas obras de Freire abordam a relevância da questão, a primeira de Freire e Shor (1986) e a segunda de Freire (2002):

A educação libertadora é, fundamentalmente, uma situação na qual tanto os professores como os alunos devem ser os que aprendem; devem ser os sujeitos cognitivos, apesar de serem diferentes. Este é, para mim, o primeiro teste da educação libertadora: que tanto os professores como os alunos sejam agentes críticos do ato de conhecer (FREIRE; SHOR; 1986, p.27).

[...] nas condições de verdadeira aprendizagem os educandos vão se transformando em reais sujeitos da construção e da reconstrução do saber ensinado, ao lado do educador, igualmente sujeito do processo. Só assim podemos falar realmente do saber ensinado, em que o objeto ensinado é apreendido na sua razão de ser e, portanto, aprendido pelos educandos (FREIRE, 2002, p. 13).

Imprescindível para a educação emancipadora é o compromisso do educador, que vislumbra com sua prática um desvelamento das condições opressoras, em um movimento ético, que fundamenta e direciona qualquer ação:

O saber alicerçante da travessia na busca da diminuição da distância entre mim e a perversa realidade dos explorados é o saber fundado na ética de que nada legitima a exploração dos homens e das mulheres pelos homens mesmos ou pelas mulheres. Mas, este saber não basta. Em primeiro lugar, é preciso que ele seja permanentemente tocado e empurrado por uma calorosa paixão que o faz quase um saber arrebatado. É preciso também que a ele se somem saberes outros da realidade concreta, da força da ideologia; saberes técnicos, em diferentes áreas, como a da comunicação. Como desocultar verdades escondidas, como desmistificar a farsa ideológica, espécie de arapuca atraente em que facilmente caímos (FREIRE, 2002, p.52-53). 
O respeito aos saberes e conhecimentos que o educando possui, legitima a prática em que educador busca dar condições para que 0 educando se torne autônomo, cidadão ciente de seus direitos e cônscio de seus deveres para com a coletividade:

[...] o inacabamento de que nos tornamos conscientes nos fez seres éticos. O respeito à autonomia e à dignidade de cada um é um imperativo ético e não um favor que podemos ou não conceder uns aos outros. Precisamente porque éticos podemos desrespeitar a rigorosidade da ética e resvalar para sua negação, por isso é imprescindível deixar claro que a possibilidade do desvio ético não pode receber outra designação senão a de transgressão. 0 professor que desrespeita a curiosidade do educando, o seu gosto estético, a sua inquietude, a sua linguagem, mais precisamente a sua sintaxe e a sua prosódia; o professor que ironiza o aluno, que 0 minimiza, que manda que "ele se ponha em seu lugar" ao mais tênue sinal de sua rebeldia legítima, tanto quando o professor que se exime do cumprimento de seu dever de propor limites à liberdade do aluno, que se furta ao dever de ensinar, de estar respeitosamente presente à experiência formadora do educando, transgride os princípios fundamentalmente éticos de nossa existência (FREIRE, 2002, p.25).

Arroyo (2010) ressalta a importância de Freire como educador e apresenta algumas considerações sobre a educação freireana. Pondera que Freire não inventou um método (p. 249), mas propôs que o educador exercite sua prática como um ato político, com clareza nas ações pedagógicas, no sentido de construir um coletivo de educandos conscientes e críticos:

Consciência [...] está atrelada às práticas culturais e políticas vivenciadas na produção da existência. Nos movimentos de libertação, sobretudo. [...] a ação pedagógica é do oprimido. A postura e conduta, a sensibilidade que Paulo espera e teve é captar esses tensos processos de produção da cultura e dos saberes populares. A esta realidade pedagógica se contrapõe a visão negativista, inculta, ignorante, inconsciente do povo, tão enraizada na política e na pedagogia (ARROYO, 2010, p.251).

A educação, como Freire concebe, é pautada por relações dialógicas, abarcando todas as pessoas da comunidade, de todas gerações. A importância da integração dos educandos de todas as idades é enfatizada, principalmente por ações comunitárias que envolvem as práticas tradicionais, que reforçam os laços de identidade e de 
continuidade das comunidades: "A educação é uma empreitada coletiva" (ARROYO, 2010, p. 252/3).

Com o reconhecimento dos valores e tradições do educando, a relação pedagógica busca entender a realidade em que vive o educando, priorizando uma apropriação de conhecimento calcada nas suas vivências. Reconhecer a realidade do educando, refletindo sobre as dinâmicas que atuam no seu contexto, propondo um processo de ressignificação, como defendiam Garcia e Valla (1996).

Freire; Faundez (1985) explicitam as dificuldades acadêmicas na compreensão dos valores e saberes de resistência:

[...] observo como a nossa formação acadêmica nos leva constantemente, com exceções, é claro, a certo gosto da descrição ou da perfilhação dos conceitos e não da apreensão do concreto, e o fazemos às vezes com a habilidade de esgrimistas. Aí temos uma diferença enorme entre nós e as classes populares que, de modo geral, descrevem o concreto. Se perguntarmos a um favelado o que é uma favela, é quase certo que responda: na favela não temos água. A sua descrição é a do concreto não a do conceito. Um de nós talvez dissesse: a favela é uma situação sócio patológica. Por isso também, como tenho salientado em outras oportunidades, a linguagem das classes populares é tão concreta quão concreta é a sua vida mesma [...] Em certo momento do processo em que o conceito deve mediar a compreensão da realidade, nos distanciamos de tal maneira do concreto que o conceito se esvazia. E como se, em certo instante, favela fosse apenas o conceito, já não a dramática situação concreta que não consigo alcançar. Vivo, então, a ruptura entre a realidade e o conceito que devia mediar a sua compreensão. Assim, em lugar de entender a mediação do conceito na compreensão do concreto, ficamos no conceito, perdidos na sua pura descrição. Pior ainda, terminamos por imobilizar o conceito, fazendo-o estático (FREIRE; FAUNDEZ, 1985, p.34-35).

Brandão apud Freire; Nogueira (1993) discorre sobre como os excluídos elaboram soluções populares:

Essas "soluções populares" para os problemas da vida social, elas revelam algo interessante, existe aí a maneira pela qual os setores populares identificam seus problemas; dito de outra forma; nessas soluções há maneiras pelas quais grupos populares se expressam "problematizados" pela realidade. Nesses envolvimentos existe "pesquisa popular", existe maneiras de produzir e apropriar-se de conhecimentos. Me pareceu que vocês refletiram alguma coisa nesse sentido: as maneiras de definir qual é o problema são também os caminhos de refletir como é o problema, e a partir daí podemos entender mais sobre a organização epistemológica própria aos 
setores ou Movimentos Populares (BRANDÃO apud FREIRE; NOGUEIRA, 1993, p.10).

É importante reconhecer nas dinâmicas sociais os movimentos de resistência e fortalece-los:

[...] na medida em que penetramos nas resistências para entendêlas, conhecendo melhor as expressões culturais, a linguagem das classes dominadas, vamos percebendo também como é que a ideologia dominante está se fazendo encarnada, quais os vazios que ela não conseguiu preencher ou os que só aparentemente preencheu em função mesma da resistência das classes populares. Não tenho dúvida nenhuma de que a compreensão do senso comum das classes populares - como estão percebendo o seu papel no mundo, na história, como elas se veem em sua relação com as lideranças políticas -, a compreensão crítica de seus sonhos, tudo isso é indispensável a qualquer esforço de luta pela transformação da sociedade. Sem compreender essas relações, sem compreender os limites da resistência das classes populares, no sentido de estimulá-la para com elas ultrapassá-los, é difícil atuar politicamente, com eficiência revolucionária [...] E o medo é uma coisa normal. Basta estar vivo, para ter medo. Mas é necessário compreender igualmente os limites do medo, para que se compreendam também os limites dos espaços de resistência. Não sei se estou sendo claro ao dizer isso. Neste sentido, me parece fundamental que o educadorpolítico e o político-educador se tornem capazes de ir aprendendo a juntar, na análise do processo em que se acham, a sua competência científica e técnica, forjada ao longo de sua experiência intelectual, à sensibilidade do concreto. Se eles forem capazes de fazer este casamento indissolúvel entre a compreensão mais rigorosa e a sensibilidade sem a qual a rigorosidade também falha, a sua prática irá se afirmar e crescer. [....] Quando às vezes me pergunto por que tanta resistência por parte de muitos de nós a viver esta comunhão com os grupos populares, a respeitar a compreensão do mundo que estão tendo; por que tanta resistência a aprender também com as massas populares, a ser simples, em nossa tentativa de comunicação com elas, recusando, de um lado, o uso de linguagem sofisticada, do outro o simplismo, no fundo arrogante e elitista, não tenho muitas respostas senão a que vê nisso tudo o ranço autoritário que nos marca. De fato, esse autoritarismo de origem burguesa e pequenoburguesa, assumido também em nome da ciência, de seu rigor, que deve ser imposto às classes populares, por causa de sua "incompetência", me faz lembrar um desses momentos de raiva que Marx revela sobretudo em sua correspondência (FREIRE; FAUNDEZ, 1985, p.29-30).

A ação do educador não é solitária, o ato pedagógico se concretiza em um contexto que abarca o coletivo; está inserida na comunidade, na realidade social: no coletivo de educadores, no coletivo de educandos. 0 reconhecimento dos saberes culturais é um resgate do valor das práticas comunitárias, intensas de significados:

Revista Exitus, Santarém/PA, Vol. 9, N. 5, p. 503 - 528, Edição Especial 2019. 
Uma outra preocupação a que jamais poderia ter se recusado a educação popular é a que tem a ver com a pesquisa epistemológica, antes ou concomitante com as práticas docentes, sobretudo em áreas camponesas. Este vem sendo, hoje, entre nós, no Brasil, um que fazer caro à etnociência. Saber como os grupos populares rurais, indígenas ou não, sabem. Como vem organizando o seu saber, ou sua ciência agronômica, por exemplo, ou a sua medicina, para o que desenvolveram uma taxionomia amplamente sistematizada das plantas, das ervas, dos matos, dos cheiros, das raízes. É interessante observar como matizam a exatidão taxionômica com promessas milagreiras. Raízes cujo chá cura, ao mesmo tempo câncer, dores de amor desfeito; ervas que combatem a impotência masculina. Folhas especiais para o resguardo da parturiente, para a espinhela caída etc. [...] recentemente pesquisas realizadas em universidades brasileiras vem constatando a exatidão de achados do saber popular. Discutir, por exemplo, com camponeses que as universidades estão comprovando alguns de seus saberes é tarefa política de alta importância pedagógica. Discussões assim podem ajudar as classes populares a ganhar confiança em si ou a aumentar o grau de confiança em que já se achem. Confiança em si mesmas tão indispensável à sua luta por um mundo melhor (FREIRE, 2006b, p. 134-135).

A relação pedagógica é dialógica e dialética, repleta de contradições que produzem significados importantes para a sua realização. As contradições são elementos importantes para a superação do senso comum e apreensão da consciência crítica. A ação pedagógica é enriquecida quando as contradições são expostas; permitem uma reflexão profunda da realidade e a analise conduz a um entendimento das dinâmicas sociais opressoras. Esta dialética é relevante para um aprofundamento das reflexões e dos encaminhamentos pedagógicos. Freire (2001a) exorta aos educadores assumir uma reflexão em que a dialética seja exposta e compreendida:

[...] a capacitação científica e técnica, a educação é prática indispensável aos seres humanos e deles específica na História como movimento, como luta. A História como possibilidade não prescinde da controvérsia, dos conflitos que, em si mesmos, já engendrariam a necessidade da educação. O que a pós-modernidade progressista nos coloca é a compreensão realmente dialética da confrontação e dos conflitos e não sua inteligência mecanicista. Digo realmente dialética porque muitas vezes a prática assim chamada é, de fato, puramente mecânica, de uma dialética domesticada. Em lugar da decretação de uma nova História sem classes sociais, sem ideologia, sem luta, sem utopia, e sem sonho, o que a cotidianidade mundial nega contundentemente, o que temos a fazer é repor o ser humano que atua, que pensa, que fala, que sonha, que ama, que odeia, que cria e recria, que sabe e ignora, que se afirma e que se nega, que

Revista Exitus, Santarém/PA, Vol. 9, N. 5, p. 503 - 528, Edição Especial 2019. 
constrói e destrói, que é tanto o que herda quanto o que adquire, no centro de nossas preocupações. Restaurar assim a significação profunda da radicalidade (FREIRE, 2001a, p.14).

O entendimento da importância do projeto educativo é relevante para a educação. Um projeto abarca o coletivo; deve ser construído com o coletivo de educandos, deve ser resultado de uma ação que esclarece e transforma, considerando a realidade, o contexto dos educandos; os conteúdos pedagógicos devem trazer elementos significativos para a comunidade. O significado de pertencimento ao coletivo é imprescindível para o êxito do projeto. Estes projetos devem ser elaborados tanto nos sistemas formais (redes formalizadas de educação - escolas), como nos sistemas informais (em movimentos sociais e organizações diversas).

Os coletivos são formados por educadores e educandos diversos, de origem e formação distintas. A diferença é uma riqueza, permite o exercício da alteridade (de se colocar no lugar do outro); abarca uma infinita possibilidade de entender a natureza humana; expõe as contradições. Proporciona a oportunidade de se relacionar na vida; propicia a capacidade de entendimento do que seja um coletivo humano, construído por um consenso que atende as necessidades comuns, respeitando as características individuais. É um exercício de cidadania, quando podemos encaminhar ações solidárias, resultantes de uma demanda que atende aos indivíduos (que juntos se reconhecem em uma comunidade). Freire (1997) abarca o conceito de multiculturalidade, uma dinâmica presente nos centros urbanos, que congregam pessoas de várias origens, etnias e vivências e que estão presentes nos espaços de ação pedagógica:

A multiculturalidade não se constitui na justaposição de culturas, muito menos no poder exacerbado de uma sobre as outras, mas liberdade conquistada, no direito assegurado de mover-se cada cultura no respeito uma à outra, correndo risco livremente de ser diferente, sem medo de ser diferente, de ser cada uma para si, somente pelo todo poderosíssimo de uma sobre as demais proibidas de ser. A tensão necessária permanentemente, entre as culturas na multiculturalidade é de natureza diferente. É a tensão a que se expõe diferentes, nas relações democráticas em que se promovem (FREIRE, 2006b, p. 79). 
Neste movimento de educação emancipatória, a alegria e esperança

são os impulsionadores da ação pedagógica, conforme Freire (2002):

Há uma relação entre a alegria necessária à atividade educativa e a esperança. A esperança de que professor e aluno juntos podemos aprender, ensinar, inquietar-nos, produzir e juntos igualmente resistir aos obstáculos à nossa alegria. Na verdade, do ponto de vista da natureza humana, a esperança não é algo que a ela se justaponha. A esperança faz parte da natureza humana [...] a esperança é um condimento indispensável à experiência histórica. Sem ela, não haveria História, mas puro determinismo. [...] Não junto minha voz à dos que, falando em paz, pedem aos oprimidos, aos esfarrapados do mundo, a sua resignação. Minha voz tem outra semântica, tem outra música. Falo da resistência, da indignação, da "justa ira" dos traídos e dos enganados. Do seu direito e do seu dever de rebelar-se contra as transgressões éticas de que são vítimas cada vez mais sofridas (FREIRE, 2002, p. 29-39).

Freire (2000b) ressalta a esperança e a utopia como relevantes para o trabalho da educação emancipadora:

Ninguém domina ninguém, ninguém rouba ninguém, ninguém discrimina ninguém, ninguém destrata ninguém sem ser legalmente punido. Nem os indivíduos, nem os povos, nem as culturas, nem as civilizações. A nossa utopia, a nossa vã insanidade é a criação de um mundo em que o poder se assente de tal maneira na ética que, sem ela, se esfacele e não sobreviva [...] em um tal mundo a grande tarefa do poder político é garantir as liberdades, os direitos e os deveres, a justiça, e não respaldar o arbítrio de uns poucos contra a debilidade das maiorias. Assim como não podemos aceitar o que venho chamando "fatalismo libertador", que implica o futuro desproblematizado, o futuro inexorável, não podemos igualmente aceitar a dominação como fatalidade. Ninguém me pode afirmar categoricamente que um mundo assim, feito de utopias, jamais será construído. Este é, afinal, o sonho substantivamente democrático a que aspiramos, se coerentemente progressistas. Sonhar com este mundo, porém, não basta para que ele se concretiza. Precisamos de lutar incessantemente para construí-los (FREIRE, 2000b, p.60).

O entendimento do papel relevante da educação, para a construção de um mundo mais justo, permite considerar que somente poderemos ter uma ação pedagógica emancipatória se atuarmos com o compromisso de desvelamento das condições opressoras, em total colaboração com os mais desfavorecidos/excluídos. 


\section{Novas perspectivas: a Pedagogia da Terra e a Teoria Crítica}

Nunes (2017) discorre sobre a obra de Gadotti (2000), que apresenta a concepção freireana de educação e a ecopedagogia, abordando as categorias em que se ampara as perspectivas atuais da educação: planetaridade, sustentabilidade, virtualidade, globalização e transdisciplinaridade (GADOTTI, 2000, p.83-84). Gadotti (2000) esclarece os desastres causados pelo modelo de desenvolvimento capitalista:

Não resta dúvida de que esta concepção do desenvolvimento coloca em cheque o consumismo do modo de produção capitalista, principal responsável pela degradação do meio ambiente e pelo esgotamento dos recursos materiais do planeta. Esse modelo de desenvolvimento, baseado no lucro e na exclusão social, não só distancia cada vez mais ricos e pobres, países desenvolvidos e subdesenvolvidos, globalizadores e globalizados. $\mathrm{Na}$ era da globalização, o capitalismo está criando, em escala mundial, um ambiente favorável ao surgimento de alternativas políticas regressivas e antidemocráticas que se aproximam do fascismo (GADOTTI, 2001, p.87).

As ações humanas modificando os espaços naturais alteram profundamente o equilíbrio climático de todo o planeta. É imprescindível o entendimento de que a ação local influencia o global. É urgente constituir-se uma educação que abarque a visão global do planeta, a noção de que todos os povos vivem em uma casa comum e que é fundamental conviver e respeitar as diferenças, sejam étnicas ou culturais, ampliando o exercício das relações dialógicas e da construção do comunitário. Gadotti (2001) propõe a ecopedagogia ou pedagogia da terra, inspirada no pensamento de Freire, destacando os princípios de autonomia, participação e diversidade cultural, em uma gestão de exercício democrático.

O desenvolvimento sustentável tem um componente educativo formidável: a preservação do meio ambiente depende de uma consciência ecológica e a formação da consciência depende da educação. É aqui que entra em cena a ecopedagogia. Ela é uma pedagogia para a promoção da aprendizagem do sentido das coisas a partir da vida cotidiana. Encontramos o sentido ao caminhar, vivenciando o contexto e o processo de abrir novos caminhos; não apenas observando o caminho. É, por isso, uma pedagogia democrática e solidária (GADOTTI, 2001, p.89). 
Em um mundo globalizado, totalmente conectado e interligado por relações virtuais, as práticas educativas devem acontecer de maneira a permitir que o educando se aproprie destes instrumentos (virtuais) e atue com criticidade, superando o senso comum. As redes sociais devem ser consideradas nas ações pedagógicas (ARROYO, 2010, p.254). O reconhecimento de sua importância permite a compreensão e sua utilização para fins educacionais. É ela uma fomentadora de questões dialéticas, contraditórias; vale explora-las e entende-las, esclarecendo o quanto as relações midiáticas interferem na compreensão do mundo e da realidade que nos cerca.

A análise das relações capitalistas indica uma degradação dos ambientes físicos e culturais, é uma relação de exploração vertiginosa dos recursos naturais. Nesta perspectiva, uma educação emancipadora deve possibilitar um entendimento sobre a preservação e manutenção dos recursos naturais, vislumbrando a construção de um mundo justo, igualitário e sustentável. A percepção de outras relações de mercado e de trabalho é prioritária, objetivando construir modos de trabalho cooperativos, em uma economia solidária e sustentável. Guattari (2001) explicita a situação da crise ecológica e argumenta para encaminhamentos necessários e possíveis:

Não haverá verdadeira resposta à crise ecológica a não ser em escala planetária e com a condição de que se opere uma autentica revolução política, social e cultural reorientando os objetivos da produção de bens materiais. Essa revolução deverá concernir, portanto, não só as relações de forças visiveis em grande escala, mas também aos domínios moleculares de sensibilidade, de inteligência e de desejo. Uma finalidade do trabalho social regulada de maneira unívoca por uma economia de lucro e por relações de poder só pode, no momento, levar a dramáticos impasses - o que fica manifesto no absurdo das tutelas econômicas que pesam sobre o Terceiro Mundo e conduzem algumas de suas regiões a uma pauperização absoluta e irreversível; fica igualmente evidente em países como a França, onde a proliferação de centrais nucleares faz pesar o risco das possíveis consequências de acidentes do tipo Chernobyl sobre uma grande parte da Europa. Sem falar do caráter quase delirante da estocagem de milhares de ogivas nucleares que, a menor falha técnica ou humana, poderiam mecanicamente conduzir a um extermínio coletivo [...] e reencontramos esse mesmo paradoxo lancinante: de um lado, o desenvolvimento continuo de novos meios técnicos científicos potencialmente capazes de resolver as problemáticas ecológicas dominantes e determinar o reequilíbrio

Revista Exitus, Santarém/PA, Vol. 9, N. 5, p. 503 - 528, Edição Especial 2019. 
das atividades socialmente uteis sobre a superfície do planeta e, de outro lado, a incapacidade das forças sociais organizadas e das formações subjetivas constituídas de se apropriar desses meios para torna-los operativos (GUATTARI, 2001, p. 9-12).

A concepção freireana de educação amplia o olhar da realidade, entendendo que é necessário considerar o planeta Terra como a casa dos seres humanos, a cidadania planetária, conforme aponta Gadotti (2001, p.116). As questões que afligem outros povos, o esgotamento dos recursos naturais, as catástrofes causadas pelos homens ou pela natureza, todas elas afetam a todos. As dinâmicas de mercado pressupõem influências no mundo todo. Os conflitos armados, em qualquer parte do mundo, impactam nas relações econômicas e sociais de todos os países, as ondas de migração modificam as estruturas sociais e transformam as dinâmicas políticas, alterando as relações entre nações e povos. Guattari (2001) entende que somente com dinâmicas sociais que contemplem e acolham a diferença, que se estruturem coletivamente (solidários e diferentes) é possível um a manutenção da vida humana no Planeta Terra:

\footnotetext{
Parece-me essencial que se organizem assim novas práticas micropolíticas e microssociais, novas solidariedades, uma nova suavidade juntamente com novas práticas estéticas e novas práticas analíticas das formações do inconsciente. Parece-me que essa é a única via possível para que as práticas sociais e políticas saiam dessa situação, quero dizer, para que elas trabalhem para a humanidade e não mais para um simples reequilíbrio permanente do Universo das semióticas capitalísticas. [...] As três ecologias deveriam ser concebidas como sendo da alçada de uma disciplina comum éticoestética e, ao mesmo tempo, como distintas uma das outras do ponto de vista das práticas que as caracterizam. Seus registros são da alçada do que chamei heterogênese, isto é, processo continuo de ressingularização. Os indivíduos devem se tornar a um só tempo solidários e cada vez mais diferentes (GUATTARI, 2001, p.35-55).
}

A pedagogia crítica apresentada na obra de Henry Giroux (1983), inspirada na perspectiva freireana de educação, discorre sobre as idéias de Paulo Freire no último capítulo da segunda parte do livro Teoria Crítica e Resistência em Educação. A referência à Freire nas obras de Giroux é citada por Morrow; Torres (1998, p. 126, 136) e Ceppas (2003, p.140). 
Giroux (1983) defende uma educação que desvele as opressões decorrentes do modelo (pós) capitalista, apontando para uma prática pedagógica que emancipe os educandos, que reconheça a importância de uma consciência crítica, que fomente a resistência ao modelo de educação imposto, uma leitura do mundo, como preconiza Freire (2006a):

\begin{abstract}
Exige sensibilidade para o capital cultural que caracteriza diferentes experiências estudantis e para as lutas nas quais os alunos realmente produzem significado através de suas experiências históricas, de posição, de família e de classe. Penetrando nessas ideologias e formas culturais, torna-se possível aos professores desvelar as mediações que dão significado à experiência escolar e entender como elas funcionam ou poderiam funcionar no interesse da acomodação, da resistência ou da mudança ativa (GIROUX, 1983, p. 210).
\end{abstract}

Ainda considerando a importância da adoção da pedagogia crítica, para uma atuação compromissada com a emancipação dos educandos, Morrow; Torres (1998) esclarecem:

A pedagogia critica tem envolvido um esforço complexo, de ligação entre a teoria crítica e as práticas educativas tal como entendidas por Freire: a relação entre reprodução societal e educação; uma sociologia estrutural do currículo; uma compreensão interacionista das atividades da sala de aula e do papel do professor, isto em termos das relações de poder que definem a educação em relação à constituição do pacto democrático de determinadas sociedades [...] a pedagogia critica foca particularmente o papel, que se encontra em mutação, da subjetividade nas relações de poder, a transformação dessas relações e o discurso enquanto acto transformador. A questão do poder e do conhecimento, bem como - modo pelo qual as manifestações de poder medeiam todas as formas de interação humana - incluindo a produção de transmissão de conhecimento - são centrais para a pedagogia crítica [...] a práxis, por seu lado, encontra-se intimamente ligada ao projeto de uma prática revolucionária, ou seja, às atividades coletivas de mobilização que acabariam por permitir à classe trabalhadora transcender a alienada divisão capitalista do trabalho (MORROW; TORRES, 1998, p.140/142).

Morrow; Torres (1998) contribuíram com reflexões sobre a educação em uma perspectiva crítica, buscando paralelos entre as obras de Habermas e Freire:

Mais claramente ainda que a filosofia de Dewey, as filosofias políticas de Freire e Habermas não temem o reconhecimento de que a 
democracia tem lugar no contexto do capitalismo; ambos criticam as relações sociais capitalistas, muito embora rejeitem noções simplistas sobre a revolução da classe trabalhadora ou alternativas socialistas. Tanto Freire como Habermas se centram na dominação e na exploração enquanto conceitos (capitalismo tardio, capitalismo dependente), mas estão essencialmente preocupados em apreender os elementos subjetivos e comunicacionais das relações de poder interpessoais, bem como as possibilidades de sua transformação (MORROW; TORRES, 1998, p.127).

A educação, sob a perspectiva crítica, é o elemento primordial para a constituição de um coletivo que vislumbre a construção de um mundo justo e igualitário, reconhecendo o Planeta Terra como sua morada. As relações devem ser respeitosas, considerando que as ações humanas são propulsoras de modos de produção que devam conceber a Terra como uma habitação humana, que deve ser cuidada e preservada. Não se pode desconhecer que as relações de poder opressoras geram, além de espoliação econômica, um modo de vida que destitui a humanidade, a essência da vida coletiva, para os seres humanos.

\section{CONSIDERAÇÕES FINAIS}

Este artigo se constituiu em uma reflexão sobre a sociedade e os encaminhamentos de uma educação emancipadora para a construção de um mundo que contemplem relações igualitárias, respeitando a vida humana e o Planeta Terra.

Alicerçadas em um texto contundente, escrito há mais de 20 anos, as reflexões emanadas naquele estudo ainda são atuais e relevantes, e revigoram as análises sobre como grupos subalternos (excluídos) mantêm ações de resistência e como a educação pode fortalecer estas ações. As pesquisas acadêmicas e ações pedagógicas poderão contribuir na consolidação das identidades culturais e no reconhecimento de saberes e valores dos grupos subalternos, revelando a riqueza do compartilhamento e das diferenças, empenhados na transformação das relações de poder.

As relações de mercado (e de poder) pós capitalistas tornam a sociedade totalmente instável, com os indivíduos vivendo relações voláteis e fluidas no trabalho, que lhes oprimem; o sentimento de insegurança é 
constante. Neste contexto a parcela que historicamente teve sua voz silenciada, os excluídos/desfavorecidos, somente poderá ter oportunidade de libertação se a educação the propiciar meios para emancipar-se, para libertar-se da relação opressora imposta pela hegemonia capitalista. É relevante que o meio acadêmico considere a fala dos excluídos e contribua para os encaminhamentos possíveis em ações que abarquem esta fala, num processo de emancipação, de mudanças nas relações de poder instituídas.

Trata-se de lutar efetivamente para que as transformações necessárias sejam encaminhadas e consolidadas, vislumbrando um mundo justo e igualitário. A perspectiva freireana de educação considera uma práxis de resistência e de emancipação para os excluídos.

Não é possível alguém se considerar rico se há indivíduos que morrem de fome ou vivem sem qualquer estrutura física que os possa abrigar. Não é possível alguém se considerar rico se os negócios humanos destroem biomas, reservas naturais e degradam o planeta. Não é possível alguém se considerar rico se a censura ou cerceamento à expressão retirem das pessoas a manifestação artística, tolham suas tradições e cultura.

A vida humana pressupõe uma concepção de sociedade que respeite as diferenças, que articule com respeito e consideração as diversas manifestações do viver, constituintes da expressão dos diferentes povos e etnias. Estas relações devem ser construídas dialogicamente, ou seja, considerando que é possível o diálogo e entendimento com outros distintos, em um processo dialético.

Nesta perspectiva, o reconhecimento da fala dos excluídos, a sua expressão para a vida, é essencial para a compreensão dos sentidos que cada povo/etnia/coletivo dá à vida humana. Somente com o exercício da escuta do outro, dos significados que o outro dá à vida é que se poderá constituir um coletivo, em busca de uma sociedade igualitária. A escuta respeitosa, os processos que envolvem estas dinâmicas dialógicas, estão presentes na concepção freireana de educação, cujos processos pedagógicos estão amparados no reconhecimento do saber e experiência 
de vida que todos possuem; em um processo que exercita a leitura do mundo, que é constituído de outros indivíduos diferentes.

A resistência que comunidades indígenas, quilombolas, caiçaras, caipiras, das periferias urbanas, dos movimentos étnicos e outros são expressões da luta pelo reconhecimento de saberes e entendimentos do que seja a vida, com as peculiaridades e riquezas culturais que colorem e formam a comunidade humana. Neste reconhecimento das riquezas dos saberes populares, em um movimento de desvelamento da realidade opressora, em reflexões coletivas e críticas sobre a sociedade atual, poderá ser possível a construção de um mundo justo e igualitário.

\section{REFERÊNCIAS}

ADORNO, T. W.; HORKHEIMER, M. Dialética do esclarecimento. Riode Janeiro, Jorge Zahar, 2002.

ARROYO, M. Paulo Freire e o Projeto Popular para o Brasil, in SOUZA, A. I. PAULO FREIRE, vida e obra. São Paulo, Expressão Popular, 2010, p. 247/258.

BAUMAN, Z. Tempos líquidos. Rio de Janeiro, Jorge Zahar Ed.,2007.

CEPPAS, F. Formação filosófica e crítica: Adorno e o ensino de filosofia em nível introdutório. Tese de Doutoramento. Orientador Leandro Augusto Marques de Coelho Konder, Rio de Janeiro, PUC-Rio, 2003.

FOUCAULT, M. Microfísica do poder. Rio de Janeiro. Graal. 1979.

FREIRE, P.; FAUNDEZ, A. Por uma Pedagogia da Pergunta. Rio de Janeiro, Paz e terra, 1985.

FREIRE, P.; SHOR, I. Medo e Ousadia - O cotidiano do Professor. Rio de Janeiro, Paz e Terra, 1986.

FREIRE, P.; NOGUEIRA, A. Que fazer, teoria e pratica em educação popular. Petrópolis, Editora Vozes, 1993.

FREIRE, P. Pedagogia da indignação: cartas pedagógicas e outros escritos. São Paulo, Editora Unesp, 2000.

FREIRE, P. Política e educação: ensaios. São Paulo, Cortez, 2001 a.

FREIRE, P. Educação e Mudança. Rio de Janeiro Paz e Terra, 2001b.

FREIRE, P. Pedagogia da Autonomia: Saberes necessários à prática educativa. Rio de Janeiro, Paz e Terra, 2002. 
FREIRE, P. Pedagogia do oprimido. Rio de Janeiro, Paz e Terra, 2006 a.

FREIRE, P. Pedagogia da Esperança: um reencontro com a Pedagogia do Oprimido. São Paulo, Paz e Terra, 2006b.

GADOTTI, M. Pedagogia da terra: ecopedagogia e educação sustentável. IN: CLACSO, Consejo Latinoamericano de Ciencias Sociales, Buenos Aires, 2001. Disponível em:

<http://bibliotecavirtual.clacso.org.ar/clacso/gt/20101010031842/4gadotti.pd f >. Acesso em: 07 jun. 2016.

GADOTTI, M. Perspectivas atuais da Educação. São Paulo em Perspectiva, São Paulo, 2000.

GARCIA, R. L.; VALLA, V. V. A fala dos excluídos, CADERNO CEDES, publicação do CEDES, Campinas, 1996.

GIROUX, H. Teoria Crítica e Resistência. Rio de Janeiro. Vozes, 1983.

GUATTARI, F. As três ecologias. Campinas, Papirus, $1^{a}$ Edição Eletrônica, 2001.

IANNI, O. A era do globalismo. Rio de Janeiro, Civilização Brasileira, 1999.

MORROW, R. A.; TORRES, C. A. Jurgen Habermas, Paulo Freire e a Pedagogia Crítica. Porto, Revista Educação, Sociedade e Culturas, 1998, n. 10.

NUNES, A. A. de S. A atualidade da Educação Freireana. Santarém, Revista Exitus, Vol. 7, No 1, p. 347-373, Set/Dez 2017.

SENNETT, R. A corrosão do caráter. Rio de Janeiro, Record, 2009.

Recebido em: 18 de abril de 2018 Aprovado em: 27 de fevereiro de 2019 